American Journal of Infectious Diseases 5 (2): 68-73, 2009

ISSN 1553-6203

(C) 2009 Science Publications

\title{
Anti-Inflammatory Activity of Vitex leucoxylon L. Bark Extracts Against Freund's Complete Adjuvant Induced Arthritis in Sprague Dawley Rat
}

\author{
Alluri V. Krishnaraju, Chundi B.M. Rao, Dodda Sundararaju, \\ Krishanu Sengupta and Golakoti Trimurtulu \\ Laila Impex R and D Centre, Unit-I, Phase-III, Jawahar Autonagar, \\ Vijayawada-520007 Andhra Pradesh, India
}

\begin{abstract}
Problem statement: Anti-inflammatory agents, particularly steroids and cyclooxygenase inhibitors are often associated with adverse side effects including, GI irritation, ulcers, hypertension and cardiac abnormalities. A safe and effective intervention is essential for the treatment of inflammatory disorders. Approach: Abstract Vitex leucoxylon L., a medicinal plant of the verbenaceae family, used in traditional medicine for relieving headache and catarrh. VL-89/185A, was obtained by bio activity-guided fractionation using 5-Lipoxygenase inhibitory activity. VL-89/185A was further tested against Freund's Complete Adjuvant (FCA) induced arthritis in Sprague Dawley (SD) rat. Results: Oral supplementation of VL-89/185A resulted in significant anti-inflammatory effects as indicated by reduction in paw edema both at 100 and $250 \mathrm{mg} \mathrm{kg}^{-1}$ doses when compared to untreated control rats. Furthermore, treatment with VL-89/185A significantly reduced circulating proinflammatory cytokines TNF- $\alpha$ and IL-1 $\beta$. The safety of VL-89/185A was established $\left(\mathrm{LD}_{50}\right.$ $>5000 \mathrm{mg} \mathrm{kg}{ }^{-1}$ body) by acute oral toxicity limit test according to OECD guidelines 425 . Conclusion: The safety and efficacy profiles indicated that VL-89/185A is a safe intervention for inflammatory disorders.
\end{abstract}

Key words: Arthritis, IL-1 $\beta$, 5-lipoxygenase, TNF- $\alpha$, Vitex leucoxylon

\section{INTRODUCTION}

Vitex leucoxylon L., commonly known as lokki, is a medicinal plant of the Verbenaceae family. It is widely distributed in Eastern Ghats and Deccan plateau in India. The leaves of $V$. leucoxylon are used in traditional medicine for relieving headache, fever and catarrh $^{[1]}$. General pharmacological studies revealed anti-psychotic, anti-depressant, analgesic, antiinflammatory, anti-parkinsonian and anti-microbial activities of aqueous and ethanolic extracts of leaves of $V$. leucoxylon ${ }^{[2]}$. Sarma et al. ${ }^{[3]}$ have studied the antiinflammatory and wound healing properties of the crude alcoholic extract of the leaves in acute inflammation model ${ }^{[3]}$. The roots and bark are astringent and the roots are reported to be used as a febrifuge. $\beta$ Sitosterol, dimethyl terphthalate, vitexin, isovitexin, agnuside and aucubin were isolated from the leaves or barks of V. leucoxylon ${ }^{[4]}$.

Inflammation is typically a protective mechanism that is triggered in response to noxious stimuli, trauma or infection to guard the body and to hasten-up the recovery process. However, inflammation that is unchecked leads to chronic inflammatory disorders. Arachidonic Acid (AA) metabolism plays a crucial role in inflammatory process and associated diseases. Some of the anti-inflammatory drugs inhibit the lipoxygenase pathway and some inhibit cyclooxygenase pathway and these two pathways can be used for potential interventions against inflammation. Unfortunately most of the anti-inflammatory drugs, particularly steroids and cyclooxygenase inhibitors are often associated with adverse side effects including, GI irritation, ulcers, hypertension and cardiac abnormalities ${ }^{[5-6]}$.

The use of herbal remedies for arthritis treatment has been gaining momentum in recent years ${ }^{[7]}$. There has been some concern over the use of COX-2 inhibitors for therapeutic intervention, especially since some of the products based on COX-2 were either withdrawn or made to carry warning by the US $\mathrm{FDA}^{[8,9]}$. 5-Lipoxygenase (5-LOX) inhibitors of herbal origin on the other hand are reported to offer significant relief and devoid of adverse effects 5-LOX inhibitors are thus becoming first choice of treatment for chronic inflammatory disease such as arthritis ${ }^{[10,11]}$. Tumor necrosis factor $\alpha$ (TNF- $\alpha)$ is a pleotropic inflammatory

Corresponding Author: Alluri V. Krishnaraju, Laila Impex R and D Centre, Unit-I, Phase-III, Jawahar Autonagar, Vijayawada-520007 Andhra Pradesh, India Tel: +91 8662545244 Fax: +91 8662546216 
cytokine produced by the immune system that suppresses tumor cell proliferation. Subsequent studies established that TNF- $\alpha$ is a key mediator of inflammation ${ }^{[12-13]}$. Interleukin-1, another important cytokine produced mainly by blood monocytes, mediates the panoply of host reactions collectively known as acute phase response. It is also known as Endogenous Pyrogen (EP), mononuclear cell factor and lymphocyte activating factor. Both IL- $1 \alpha$ and IL- $1 \beta$ can trigger fever by enhancing prostaglandin $\mathrm{E}_{2}\left(\mathrm{PGE}_{2}\right)$ synthesis by the vascular endothelium of the hypothalamus and can stimulate $\mathrm{T}$ cell proliferation. The cytokine interleukin 1 beta (IL-1 $\beta$ ) is a potent mediator in response to infection and injury ${ }^{[14]}$.

$V$. leucoxylon leaf extracts were previously tested for anti-inflammatory activity using carrageenan induced paw edema. However the bark extracts $V$. leucoxylon were not tested using arthritis or chronic inflammatory models to prove the efficacy of $V$. leucoxylon. Hence, we sought to study the 5-lipoxygenase inhibitory activity of $V$. leucoxylon bark extracts and its anti-arthritis potential against FCA induced arthritis.

\section{MATERIALS AND METHODS}

Plant material and chemicals: The plant material (bark of V. leucoxylon L) was collected from Raapur reserve forest Veligonda range, Nellore District, (South-Eastern Ghats) of Andhra Pradesh, in September 2005 and identified by Dr. K. Narasimha Reddy. A voucher specimen (No. LIH 6577) was deposited in the raw drug specimen depository of the Taxonomy Division at Laila Impex R and D Centre, Vijayawada, India. Powdered material (750 g) of V. leucoxylon bark, was extracted with hexane $(2 \mathrm{~L})$, ethyl acetate $(1.75 \mathrm{~L})$ and methanol $(1.75 \mathrm{~L})$ using a Soxhlet apparatus and the spent material was then successively extracted with aqueous methanol $(80 \%, 2 \mathrm{~L})$ and water $(2 \mathrm{~L})$. The extracts were filtered, concentrated, independently and dried under reduced pressure to obtain, hexane $(8.2 \mathrm{~g})$, ethyl acetate (4.5 g), methanol (40 g), aqueous methanol (42 g) and water (38 g) extracts and then used as test substances. A Potent 5-lipoxygenase (5-LOX) inhibitory fraction obtained through bioactivity guided fractionation was used for in vivo efficacy and toxicity studies. Aqueous methanol extract of $V$. leucoxylon (VL-89/185A) bark was found to be the most potent 5LOX inhibitor. It was used for in vivo study. NDGA, ethanol, linoleic acid, potassiumdihydrogenphosphate, dipotassiumhydrogenphosphate and all other reagents unless otherwise mentioned were obtained from Sigma Chemical Company (St. Lousis, MO).
In vitro 5-Lipoxygenase inhibition: 5-LOX enzyme inhibitory activity of $V$. leucoxylon extracts was measured using the method of Reddanna et al. ${ }^{[15]}$ modified by Ulusu et al. ${ }^{[16]}$ The assay mixture contained $80 \mu \mathrm{M}$ linoleic acid and $10 \mu \mathrm{l}$ potato 5-LOX in $50 \mathrm{mM}$ phosphate buffer $(\mathrm{pH} \mathrm{6.3)}$. The reaction was initiated by the addition of enzyme buffer mix to linoleic acid and the enzyme activity was monitored as the increase in absorbance at $234 \mathrm{~nm}$. The reaction was monitored for $120 \mathrm{sec}$ and the inhibitory potential of the test substances was measured by incubating various concentrations of test substances for two minutes before addition of linoleic acid. All assays were performed in triplicate. Percentage inhibition was calculated by comparing slope of test substances with that of enzyme activity. The data was shown in Fig. 1.

FCA induced arthritis in sprague dawley rats: Male and female SD rats obtained from National Institute of Nutrition (NIN), Hyderabad, were housed under standard laboratory conditions with free access to food and water. The temperature $\left(20-24^{\circ} \mathrm{C}\right)$, relative humidity (45-70\%) and a 12-h light/dark cycle were maintained. The IAEC of Laila Impex R and D Centre has approved this protocol (LI 061006B). All animal procedures were performed in strict compliance with the guidelines issued by the CPCSEA. Adjuvant induced arthritis experiment was done according to the method of Chang et al. ${ }^{[17]}$, which was modified by Roy et al. ${ }^{[18]}$ Briefly, the healthy SD rats were selected, acclimatized and then orally supplemented with VL$89 / 185 \mathrm{~A}$ at doses 100 or $250 \mathrm{mg} \mathrm{kg}^{-1}$ body weight or prednisolone at $10 \mathrm{mg} \mathrm{kg}^{-1}$ in $10 \mathrm{~mL} \mathrm{~kg}$ of $0.5 \%$ $\mathrm{CMC}$ for four weeks. The control group received the same volume of vehicle $(0.5 \% \mathrm{CMC})$ orally. On 14 th day of treatment, $50 \mu \mathrm{L}$ Freund's Complete Adjuvant (FCA) was injected subcutaneously in to the subplantar region of left hind paw. Blood samples were drawn on 3rd, 7th and 14th day after induction, centrifuged in refrigerated centrifuge and the serum aliquots were frozen at $-80^{\circ} \mathrm{C}$ for analysis of proinflammatory cytokines. The paw volume was measured by independent observers with no knowledge of treatment allocation before and after the injection of Freund's adjuvant and continued daily there after for 14 days using water displacement plethysmometer (Ugo basile, Italy). The difference in volume $\left(\mathrm{V}_{13}\right)$ between paw volume on day 13 after injection and that on the day $\left(\mathrm{V}_{0}\right)$ of injection is calculated to estimate inflammatory response. Percent inhibition $=[($ Mean Edema of control gp-Mean Edema of treated gp)/Mean Edema of control gp] $\times 100$. The data was shown in Fig. 2. 


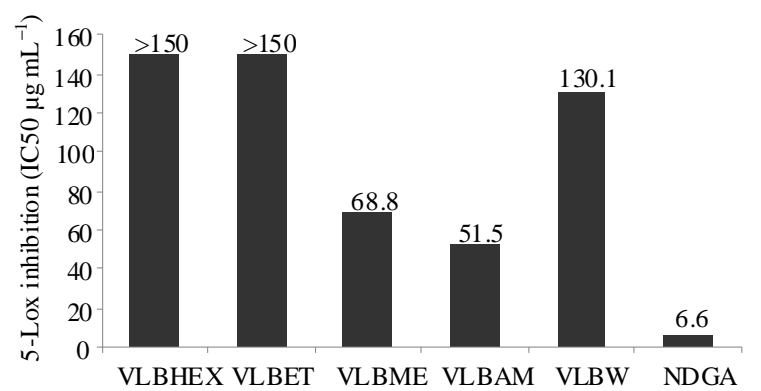

Fig. 1: Bar diagrammatic representations of in vitro 5lipoxygenase inhibitory activity. The bars represent, $V$. leucoxylonbark hexane, ethyl acetate, methanol, aqueous methanol and water extracts; and a positive control nordihydroguiaritic acid. Each bar represents $50 \%$ enzyme inhibitory concentration $\left(\mathrm{IC}_{50}\right.$ in $\left.\mu \mathrm{g} \mathrm{mL} \mathrm{L}^{-1}\right)$

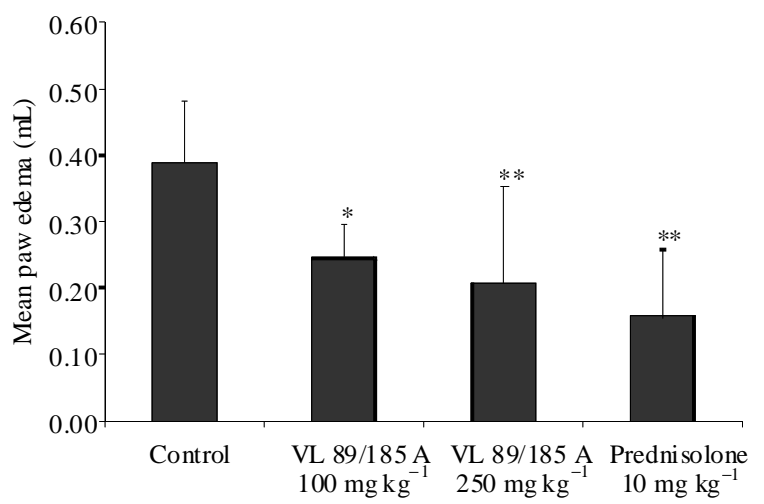

Fig. 2: Bar diagrammatic representations of paw edema in different group of animals. After 13 days of FCA challenge, paw volumes were measured using water displacement plethysmometer and edema was calculated by subtracting initial paw volume $\mathrm{V}_{0}$ from final paw volume $\mathrm{V}_{13}$. The bars represent, control, VL 89/185A 100, 250 and prednisolone $10 \mathrm{mg} \mathrm{kg}^{-1}$. Each bar represents mean \pm SEM. $\mathrm{N}=6, *: \mathrm{p}<0.05$ and $* *: \mathrm{p}<0.005$ (Vs control)

Measurement of serum cytokines: The serum TNF- $\alpha$ or IL-1 $\beta$ concentrations were measured as per the instructions provided with the rat cytokine ELISA development kits ( $\mathrm{R}$ and D Systems, USA). Briefly, 0.1 $\mu \mathrm{g}$ of either TNF- $\alpha$ or IL-1 $\beta$ capture antibody was coated onto each well of 96-well ELISA plates (Maxisorp, NUNC, Denmark). The non-specific sites in the reactive wells were blocked with $1 \%$ BSA and thereafter $50 \mu \mathrm{L}$ of rat serum sample from each animal

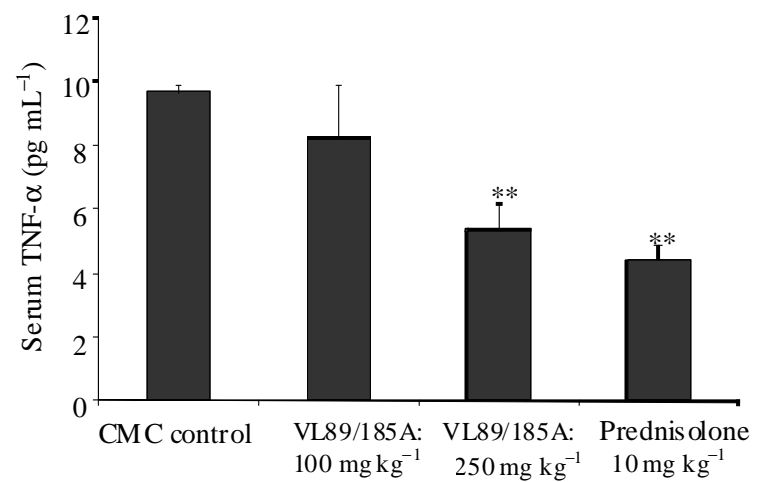

(a)

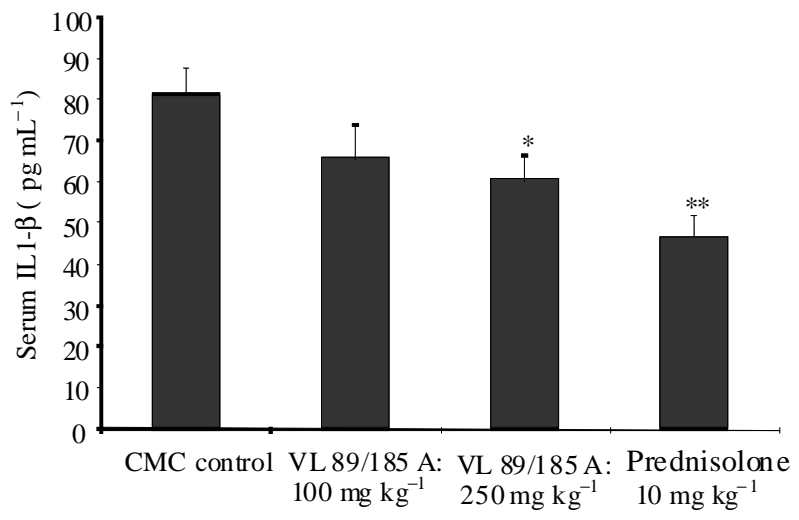

(b)

Fig. 3: Bar diagrammatic representations of serum TNF- $\alpha(\mathrm{A}$ and IL-1 $\beta \mathrm{B}$ concentrations in different group of animals. After 14 days of FCA challenge, serum TNF- $\alpha$ and IL- $1 \beta$ were quantitatively measured by enzyme-immuno assay kit ( $\mathrm{R}$ and D Systems, USA). The bars represent, control, VL 89/185A 100, 250 and prednisolone $10 \mathrm{mg} \mathrm{kg}^{-1}$. Each bar represents mean \pm SEM. $\mathrm{N}=4, *: \mathrm{p}<0.05$ and $* *: \mathrm{p}<0.005$ (Vs control)

was added separately to each well and incubated for $2 \mathrm{~h}$ at room temperature. The specifically bound TNF- $\alpha$ or IL-1 $\beta$ was probed with respective detection antibodies and the antigen-antibody reactions were detected with avidin-peroxidase conjugate. Finally, the specific color reactions were developed by adding TMB substrate and were read at $405 \mathrm{~nm}$ in a micro plate ELISA reader (BioRad, USA). The mean of each group was estimated and the data is shown in Fig. 3.

Acute oral toxicity: Acute oral toxicity of VL-89/185A was studied according to OECD guidelines, \#425; "acute oral toxicity up-and-down procedure" ${ }^{,[19]}$. The 
study protocol (LI 050403) was approved by Institutional Animal Ethics Committee (IAEC) and the study was conducted at the animal facility of Laila Impex $\mathrm{R}$ and $\mathrm{D}$ Centre, which was registered by CPCSEA (Reg No 204/CPCSEA). Three Female Sprague-Dawley rats (age: 9-10 weeks), obtained from National Institute of Nutrition (Hyderabad, India), were allowed free access to standard rodent diet supplied by Tetragon Chemie (Bangalore, India) and provided filtered U.V. exposed water ad libitum. The animals were acclimated to laboratory conditions for 7 days prior to initiation of dosing. The animal room was kept at a controlled temperature $\left(20-24^{\circ} \mathrm{C}\right)$, humidity (45$70 \%$ ) and light (12 h light $12 \mathrm{~h}^{-1}$ dark). A limit test was performed on three female Sprague-Dawley (SD) rats. Dose formulation of VL-89/185A was prepared prior to administration, by suspending VL-89/185A in $0.5 \%$ $\mathrm{CMC}$ in water to obtain a final concentration of $500 \mathrm{mg} \mathrm{mL}^{-1}$ to allow a constant dosage volume of $10 \mathrm{~mL} \mathrm{~kg}$ body $^{-1}$ weight. Female rats were administered VL-89/185A by oral gavage. The rats were fasted overnight prior to dosing and returned to feeding 3 $\mathrm{h}$ after dosing. On the day of dosing, all the animals were observed for mortality and signs of intoxication at 1, 3, 4 and $5 \mathrm{~h}$ following dosing and thereafter they were observed twice a day for 14 days. Body weights of rats were individually recorded before dosing (day 0) and thereafter continued at weekly intervals. All animals were sacrificed at the end of the observation period and subjected to a complete gross necropsy.

Statistical analysis: The in vivo data were analyzed using ANOVA, all values reported as mean \pm SEM from 5-6 samples. Statistical significance was set at $\mathrm{p}<0.05$.

\section{RESULTS}

\section{5-Lipoxygenase enzyme inhibitory activity:} According to the results shown in Fig. 1, it is quite evident that methanol and aqueous methanol and water extract of $V$. leucoxylon bark exhibited dose dependent 5-lipoxygenase inhibitory activity with $\mathrm{IC}_{50}$ values 68.8, 51.5 and $130.1 \mu \mathrm{g} \mathrm{mL} \mathrm{mL}^{-1}$ respectively. The methanol and aqueous methanol extracts exhibited moderate 5-Lipoxygenase inhibitory activity, when compared with known standard NDGA.

FCA induced arthritis: Oral supplementation of $V$. leucoxylon active fraction VL-89/185A resulted in dose dependent and statistically significant efficacy against Freund's Complete Adjuvant induced arthritis in SD rats. Both 100 and $250 \mathrm{mg} \mathrm{kg}^{-1}$ doses of VL89/185A showed significant inhibition of paw edema with percentage inhibitions 36.92 and $46.41 \%$ respectively. The positive control, prednisolone (10 $\mathrm{mg} \mathrm{kg}^{-1}$ ) exhibited better inhibition (59.74\%) in paw edema. FCA injected, vehicle control rats showed significant elevation of proinflammatory cytokine TNF$\alpha$ on 14 th day after induction relative to healthy control animals. Oral supplementation of VL-89/185A resulted in statistically significant reduction of TNF- $\alpha$ in serum at a dose of $250 \mathrm{mg} \mathrm{kg}^{-1}$. The positive control prednisolone exhibited highly significant reduction of TNF- $\alpha$ in serum at a dose of $10 \mathrm{mg} \mathrm{kg}^{-1}$ Fig. 3a. Circulating levels of IL-1 $\beta$ were higher in FCA induced animals. Oral treatment of FCA induced rats with VL89/185A had dose dependent effect on circulating IL-1 $\beta$ at doses of 100 and $250 \mathrm{mg} \mathrm{kg}^{-1}$. FCA induced rats treated with prednisolone $\left(10 \mathrm{mg} \mathrm{kg}^{-1}\right)$ resulted in highly significant reduction of circulating IL-1 $\beta$ as shown in Fig. $3 b$.

Acute oral toxicity study: In the present study, single oral administration of VL-89/185A was made to female $\mathrm{SD}$ rats to assess its systemic toxicity, as a limit test. VL-89/185A, at the limit dose level of $5,000 \mathrm{mg} \mathrm{kg}^{-1}$ body weight did not caused mortality in any of the three treated test animals (three female SD rats) and did not induced any signs of evident toxicity following dosing and during the post treatment observation period of 14 days. The body weight gain found to be normal and no gross pathological alterations were encountered in any of the rats, as evident at terminal necropsy. Based on these results the median lethal dose $\left(\mathrm{LD}_{50}\right)$ of VL89/185A after single oral administration in female SD rats was found to be greater than $5,000 \mathrm{mg} \mathrm{kg}^{-1}$ body weight under the conditions of this study.

\section{DISCUSSION}

Many Plant derived compounds have tested for their ability to block leukotriene synthesis in isolated cells from rat, mouse or human sources. The polyphenol, nordihydroguaretic acid (NDGA) from the Mexican desert plant Larrea divaricata was the first plant-derived 5-Lipoxygenase inhibitor ${ }^{[20]}$. Plant derived chemical constituents like flavanoids, coumarins, Quinones, pentacyclic triterpenes, sesquiterpenes, alkaloids and polyacetylates have been reported to be 5-Lipoxygenase inhibitors $^{[21,22]}$. In the present study, VL-89/185A from barks of $V$. leucoxylon showed 5-lipoxygenase inhibitory activity. Bio-assay (5-Lipoxygenase inhibition) guided fractionation yielded VL-89/185A as the most active fraction. This active fraction was used for in vivo antiinflammatory study. 
Freund's Complete Adjuvant (FCA) induced arthritis and collagen induced arthritis are the two animal models which are extensively used to study antiarthritis potential of therapeutic interventions. Paw swelling is one of the major factors in assessing the degree of inflammation and efficacy of test drugs ${ }^{[23,24]}$. The anti-inflammatory efficacy of some plants of vitex genus including $V$. altissima were evaluated in rat models of paw edema ${ }^{[21,25]}$. In the present investigation, various bark extractives and fractions were screened by in vitro 5-LOX enzyme inhibitory assay. The most potent 5-LOX inhibitory fraction (VL-89/185A) was then evaluated for in vivo efficacy against FCA induced arthritis in rats. VL-89/185A obtained from the bark showed dose dependent efficacy with 36.92 and $46.41 \%$ inhibition of paw edema at 100 and $250 \mathrm{mg} \mathrm{kg}{ }^{-1}$ doses respectively. Where as standard prednisolone showed $59.74 \%$ inhibition at a dose of $10 \mathrm{mg} \mathrm{kg}^{-1}$ body weight. Elevated level of TNF- $\alpha$ has been reported in arthritis patients and in experimentally induced arthritis Philippe et al. ${ }^{[26]}$ TNF- $\alpha$ and IL-1 $\beta$ are potent proinflammatory cytokines capable of inducing multiple signaling cascades that can serve in host defense and paradoxically contribute to inflammatory tissue injury ${ }^{[27]}$. Oral supplementation of VL-89/185 A obtained from the bark of $V$. leucoxylon resulted in dose dependent and statistically significant reduction of circulating TNF- $\alpha$ and IL-1 $\beta$. As the active fraction has shown significant anti-inflammatory activity, an acute oral toxicity study was initiated. Acute oral toxicity limit test of VL-89/185A revealed that it is non-toxic up to $5000 \mathrm{mg} \mathrm{kg}^{-1}$ body weight in female SD rats

\section{CONCLUSION}

VL-89/185A exhibited significant inhibition of paw edema in FCA induced arthritis. The reduction in circulating cytokines TNF- $\alpha$ and IL- $1 \beta$ further confirmed its efficacy. Based on foregoing preclinical efficacy and safety data, the 5-LOX inhibitory fraction VL-89/185A obtained from V. leucoxylon bark extract can be considered as safe and effective intervention for inflammatory diseases including arthritis.

\section{ACKNOWLEDGEMENT}

The researchers thank Sri G. Ganga Raju, Chairman, Mr G. Rama Raju, Director Laila Group and $\mathrm{Mr} \mathrm{B}$. Kiran CEO, Laila Nutraceuticals for encouragement and support. The researchers thank Dr. K.N. Reddy, (Taxanomist, Laila Impex R and D Centre) for collection and authentication of the plant material.

\section{REFERENCES}

1. Chanda Y.R., 1982. The wealth of India:A dictionary of Indian Raw materials and Industrial products; Publication and Information Directorate, CSIR, New Delhi, pp: 520-521. http://www.niscair.res.in/activitiesandservices/prod ucts/woi1.htm

2. Makwana, H.G., B. Ravishankar, V.J. Shukla, N.P. Vijayan, C.K. Sasikala, V.N. Saraswathy and S.V. Bhatt, 1994. General pharmacology of Vitex leucoxylon linn leaves. Indian J. Physiol. Pharmacol., $\quad 38$ : 95-100. http://indianmedicine.eldoc.ub.rug.nl/root/M/65647/

3. Sarma, S.P., K.S. Aithal, K.K. Srinivasan, A.L. Udupa, V. Kumar, D.R. Kulkarni and P.K. Rajagopal, 1990. Antiinflammatory and wound healing activities of the crude alcoholic extract and flavonoids of Vitex leucoxylon. Fitoterapia, 61: 263-265.

4. Rao, R.V.K., T. Satyanarayana and R. Jena, 1997. Phytochemical studies on Vitex leucoxylon L. Indian Drugs, 34: 50-51.

http://cat.inist.fr/?aModele $=$ afficheN\&cpsidt $=10572622$

5. William, L.S., 1989. The eicosanoids and their biochemical mechanism of action. Biochem. J., 259: 315-324. PMID: 2655580

6. Wolfe, M.M. and R.L. David, 1999. Lichtenstein: Gastrointestinal toxicity of Non steroidal antiinflammatory drugs. N. Engl. J. Med., 340: 1888-1899. http://content.nejm.org/cgi/content/extract/340/24/ 1888

7. Chrubasik, J.E., B.D. Roufogalis and S. Chrubasik, 2007. Evidence of effectiveness of herbal antiinflammatory drugs in the treatment of painful osteoarthritis and chronic low back pain. Phytother. Res., 21: 675-683. DOI: 10.1002/ptr.2142

8. Naesdal, J. and K. Brown, 2006. NSAIDassociated adverse effects and acid control aids to prevent them: A review of current treatment options. Drug Safe., 29: 119-32. http://www.drugsafety.adisonline.com/pt/re/drs/abs tract.00002018-200629020-00002

9. Salmon, S.D., 2006. Cyclooxygenase-2 inhibitors and cardiovascular risk. Curr. Opin. Cardiol., 21: 613-617. DOI: 10.1097/01.hco.0000245740.85829.4f

10. Krishanu, S., A.V. Krishnaraju, A.R. Satish, S. Mishra, G. Trimurtulu, K.V.S. Sarma, D. Dey and S.P. Raychaudhuri, 2008. A double blind, randomized, placebo controlled study of the efficacy and safety of 5-Loxin ${ }^{\circledR}$ for treatment of osteoarthritis of the knee. Arthrit. Res. Ther., 10: 85. DOI: $10.1186 / a r 2461$ 
11. Oliver, W., 2007. Inhibition of 5-Lipoxygenase product synthesis by natural compounds of plant origin. Planta Med., 73: 1331-1357. DOI: 10.1055/s-2007-990242

12. Warren, J.S., P.A. Ward and K.J. Johnson, 1988. Tumor necrosis factor: A plurifunctional mediator of acute inflammation. Modern Pathol., 1: 242-247. http://www.ncbi.nlm.nih.gov/pubmed/2853361

13. Vasanthi, P., G. Nalini and G. Rajasekhar, 2007. Role of tumor necrosis factor-alpha in rheutomatoid arthritis: A review. APLAR J. Rheumatol., 10: 270-274. DOI: 10.1111/j.14798077.2007.00305.x

14. LimeiLi, Z.F., R. Jianke, S. Ruilin, L. Zhihui, S. Zhejin, W. Long, S. Xia, Y. Jun, W. Zhugang and F. Jian, 2008. Functional imaging of interleukin 1 beta expression in inflammatory process using bioluminescence imaging in transgenic mice. BMC. Immunol., 9: 49. DOI: 10.1186/1471-2172-9-49

15. Reddenna, P., J. Whelan, K.R. Maddipati and C.C. Reddy, 1990. Purification of arachidonate 5Lipoxygenase from potato tubers. Methods Enzymol., 187: 268-277. http://www.ncbi.nlm.nih.gov/pubmed/2233349

16. Ulusu, N.N., D. Ercil, M.K. Sakar and E.F. Tezcan, 2002. Abietic acid inhibits lipoxygenase activity. Phytother. Res., 16: 88-90. DOI: 10.1002/ptr.983

17. Yi-Han, C., C.M. Pearson and C. Louis, 1981. Adjuvant polyarthritis. $\mathrm{V}$. Induction by $\mathrm{N}$ acetylmuramyl-L-alanyl-D-isoglutamine, the smallest peptide subunit of bacterial peptidoglycan. J. Exp. Med., 153: 1021-1026. http://jem.rupress.org/cgi/content/abstract/153/4/1021

18. Roy, S., S. Khanna, A.V. Krishnaraju, G.V. Subbaraju, T. Yasmin, D. Bagchi and C.K. Sen, 2006. Regulation of vascular responses to inflammation: Inducible matrix metalloproteinase- 3 expression in human microvascular endothelial cells is sensitive to antiinflammatory boswellia. Antioxid. Redox. Signal, 8: 653-60. DOI: 10.1089/ars.2006.8.653

19. Organization for Economic Co-operation and Development, 2008. OECD guideline for the testing of chemicals, acute oral toxicity: Up-anddown procedure.

http://www.oecdbookshop.org/oecd/display.asp?la $\mathrm{ng}=\mathrm{fr} \& \mathrm{sf} 1=\mathrm{DI} \& \mathrm{st} 1=5 \mathrm{LMQCR} 2 \mathrm{~K} 7 \mathrm{MS} 0$
20. Bokoch, G.M. and P.W. Reed, 1981. Evidence for inhibition of leukotriene A4 synthesis by 5,8,11,14eicosatetranoic acid in guinea polymorphonuclear leukocytes. J. Biol. Chem., 256: 4156-4159. http://www.jbc.org/cgi/reprint/256/9/4156

21. Sridhar, C., G.V. Subbaraju, Y. Venkateswarulu and T.V Raju, 2004. New acylated iridoid glucosides from Vitex altissima. J. Nat. Prod., 67: 2012-2016. DOI: 10.1021/np040117r

22. Werz, O., 2007. Inhibition of 5-Lipoxygenase product synthesis by natural compounds of plant origin. Planta Med., 73: 1331-1357. DOI: 10.1055/s-2007-990242

23. Mizushima, Y., W. Tsukada and T. Akimoto, 1972. A modification of rat adjuvant arthritis for testing antirheumatic drugs. J. Pharm. Pharmacol., 24: 781-785. http://www.ncbi.nlm.nih.gov/pubmed/4403974

24. Begum, V.H. and J. Sadique, 1988. Long term effect of herbal drug Withania somnifera on adjuvant induced arthritis in rats. Indian J. Exp. Biol., 26: 877-882.

http://www.ncbi.nlm.nih.gov/sites/entrez

25. Sridhar, C., K.V. Rao and G.V. Subbaraju, 2005. Flavonoids, triterpenoids and a lignan from Vitex altissima. Phytochemistry, 66: 1707-1712. DOI: 10.1016/j.physletb.2003.10.071

26. Philippe, L., P. Gegout-pottie, C. Guingamp, K. Bordji, B. Terlain, P. Netter and P. Gillet, 1997. Relations between functional, inflammatory and degenerative parameters during adjuvant arthritis in rats. Am. J. Physiol., 273: R1550-R1556. http://ajpregu.physiology.org/cgi/reprint/273/4/R1550

27. McCulloch, C.A., G.P. Downey and H. El-Gabalawy, 2006. Signalling platforms that modulate inflammatory response: New targets for drug development. Nature Rev. Drug Discov., 5: 864-876. DOI: $10.1038 / \mathrm{nrd} 2109$ 